\title{
Mapping Regional Drought Vulnerability: A Case Study
}

\author{
M. Karamouz ${ }^{\text {a* }}$, A. Zeynolabedin ${ }^{\text {b }}$, M.A. Olyaei ${ }^{\mathrm{c}}$ \\ ${ }^{a}$ Professor, School of Civil Engineering, University of Tehran, Tehran, Iran, karamouz@ut.ac.ir \\ ${ }^{\mathrm{b}}$ Research assistant, School of Civil Engineering, University of Tehran, Tehran, Iran, aminzynolabedin@ut.ac.ir \\ ${ }^{c}$ Ph.D. Candidate, School of Civil Engineering, University of Tehran, Tehran, Iran, ma.olyaie@ut.ac.ir
}

KEY WORDS: Drought, MCDM, Regional Assessment, Climate Variability, Vulnerability Maps, GIS

\begin{abstract}
:
Drought is among the natural disaster that causes damages and affects many people's life in many part of the world including in Iran. Recently, some factors such as climate variability and the impact of climate change have influenced drought frequency and intensity in many parts of the world. Drought can be divided into four categories of meteorological, hydrological, agricultural and socialeconomic. In meteorological the important feature is lack of rainfall. In hydrological drought river flows and dam storage are considered. Lack of soil moisture is the key factor in agricultural droughts while in social-economic type of drought the relation between supply and demand and social-economic damages due to water deficiency is studied. While the first three types relates to the lack of some hydrological characteristics, social-economic type of drought is actually the consequence of other types expressed in monetary values. Many indices are used in assessing drought; each has its own advantages and disadvantages and can be used for specific types of drought. Therefore knowing the types of drought can provide a better understanding of shortages and their characteristics. Drought vulnerability is a concept which shows the likelihood of damages from hazard in a particular place by focusing on the system status prior to the disaster. Drought vulnerability has been viewed as a potential for losses in the region due to water deficiency at the time of drought. In this study the application of vulnerability concept in drought management in East Azarbaijan province in Iran is investigated by providing vulnerability maps which demonstrates spatial characteristics of drought vulnerability. In the first step, certain governing parameters in drought analysis such as precipitation, temperature, land use, topography, solar radiation and ground water elevation have been investigated in the region. They are described in details and calculated in suitable time series. Vulnerabilities are ranked in 5 intervals and for each parameter vulnerability maps are prepared in GIS environment. Selection of theses parameters are based on factors such as regional features and availability of data. Considering the fact that the aforementioned parameters have different level of importance in vulnerability maps, different weights are assigned to the parameters considering how critical each parameter is in the overall drought analysis. Expert's opinion is selected in assigning weights. A multi-criteria decision making (MCDM) framework is used to check the consistency of the provided information. Then the weighted maps are overlaid to find the overall vulnerability map. The map shows very low, low, medium, intense and very intense regional vulnerabilities. According to the results, the west part of East Azarbaijan province is the most vulnerable region to drought which is expected due to the vicinity of this part to Urumia Lake that has been lost most of its water during the last decades. The least vulnerable part seems to be the Eastern part of the province with longer lasting resources. Taking into consideration that Caspian Sea is near this part with high precipitation record, the outcome of this study is in line with the general expectations. The result of this study can be used for preparedness planning and for allocating resources for facing droughts in this region.
\end{abstract}

\section{INTRODUCTION}

One of the complex natural hazards that have extreme effects on society, environment and economy is drought. So realizing its features can provide a better preparedness to face it. Various definitions have been provided for drought but in general the lack of water resources in a specific period in a geographical area is considered as drought (Rossi, 2000) which implies this phenomenon as a regional hazard. Intensity, duration and area extent are three important features in drought (Rossi et al., 1992).

Drought can be divided into four categories which are meteorological, hydrological, agricultural and social-economic (Wilhite and Glantz, 1985; Rasmussen et al., 1993). In meteorological the important feature is lack of rainfall. In hydrological drought river flows and dam capacities are considered. Low soil moisture is the key factor in agricultural droughts while in social-economic type of drought the relation between supply and demand and social-economic damages due to water deficiency is studied. While the first three types relates to the lack of some hydrological characteristics, socialeconomic type of drought is actually the consequence of other droughts in terms of monetary losses (Keyantash and Dracup, 2002). There are a number of indices used in assessing drought; each has its own advantages and disadvantages and can be used for a specific types of drought. Therefore depending on the types of drought a region is concerned about, the assessment and monitoring of that could be significantly different.

\footnotetext{
* Corresponding author
} 
Dziegielewski et al. (1992) works can be noted in the socialeconomic drought field. After examining the economic consequences water supply shortage, he recommended longterm drought management plan for Phoenix in the United States. About hydrological drought, Garen (1993) research can be referred. He investigated Flat Head river flow in Montana using the revised index of surface water supply index which is called SWSI (Shafer and Dezman 1982). Shin et al. (2000) analyzed regional drought using neutral networks. Karamouz et al. (2004) analyzed hydrological and agricultural droughts in the central region of Iran using statistical analysis. In this study a water balance model has been developed for estimating hydrological and agricultural parameters in order to calculate excess rainfall under normal conditions that is required for determining PDSI and soil moisture anomaly $\mathrm{Z}$ indices. Karamouz et al. (2009) presented a hybrid index for meteorological, agricultural and hydrological drought and compared the results one by one. Karamouz et al. (2013) developed an integrated drought evaluation and monitoring system for Aharchay river basin.

Vulnerability is the important concepts in natural hazards including drought (Klein et al., 2003). Vulnerability shows the likelihood of damages from hazard in a certain place by focusing on the system status prior to the disaster (Zhou et al., 2010). However, there are some other definitions of vulnerability (Cutter et al., 2003; Etkin et al., 2004; Turner et al., 2003; Gallopin, 2006). Vulnerability can be studied in four concepts: exposure, susceptibility, coping capacity and adaptive capacity (Neema et al., 2010).

Many studies have been done in applying vulnerability concept in drought. Anderson (1995) delivered a general framework for assessing vulnerability. Bohle et al. (1994) investigated climate change and social vulnerability toward a sociology and geography of food insecurity. Lourens (1995) developed a system for drought monitoring and severity assessment. Liu and Kogan (1996) developed a way to monitor regional drought using the vegetation condition index. Chang et al. (1997) developed a GIS procedure for the study of evaporation and infiltration in case of drought. Keenan and Krannich (1997) investigated the social context of perceived drought vulnerability. Wilhelmi and Wilhite (2000) assessed vulnerability to agricultural drought in Nebraska. Jackson (2001) assessed and mapped drought hazard for Nevis. Some researchers have assessed specific drought vulnerability for a region. Eriyagama et al. (2009) mapped drought pattern and impacts as a global perspective. Slejko et al. (2010) assessed agricultural drought vulnerability for the west part of Slovenia which results in a vulnerability map that provide decision makers with information about which region is under a risk of being affected by drought. Moring et al. (2012) mapped drought vulnerability on the basis of some parameters like climate, land use and soil parameters using GIS technique.

The aim of this study is to assess the spatial vulnerability of the region by applying some important parameters.

In general, previous studies on droughts mostly have paid attention to drought assessment index calculation, determination of its severity, and detection the threshold of drought occurrence. In vulnerability concept, a more comprehensive approach has been implemented by considering more parameters than previous works in assessing drought vulnerability maps.

In the following section, methodology has been described in details and results have been presented cussed and finally a summary and conclusion is given.

\section{METHODOLOGY}

In the following section the procedure for creating vulnerability maps is discussed. To achieve this objective, first, the vulnerability maps of the region is obtained by analyzing and overlaying the spatial maps of important parameters in drought context like topography, solar radiation, precipitation, temperature, land use and ground water elevation.

\subsection{Vulnerability Assessment}

Drought vulnerability has been viewed as a potential for losses in a region due to water deficiency at the time of drought. In this section, development of drought vulnerability map is discussed extending the methodology utilized by Slejko (2010). For this purpose six parameters have been selected which are precipitation, temperature, solar radiation, slope, land use and ground water level. The data needed was obtained from Iran Meteorological Organization (IRIMO), Water Resources Management Company and Forests, Range, Watershed Management Organization which is showed in Table 1 by details. Data duration for all parameters is from 2001 until 2011.

\begin{tabular}{|c|c|}
\hline $\begin{array}{c}\text { Precipitation, temperature, } \\
\text { solar radiation, ground water } \\
\text { level }\end{array}$ & $\begin{array}{c}\text { Meteorological Organization } \\
\text { (IRIMO) }\end{array}$ \\
\hline DEM files for slope map & $\begin{array}{c}\text { Water Resources Management } \\
\text { Company }\end{array}$ \\
\hline Land use & $\begin{array}{c}\text { Forests, Range, Watershed } \\
\text { Management Organization }\end{array}$ \\
\hline
\end{tabular}

Table 1- Data resources from agencies in Iran

For each parameter a category map has been created using GIS which shows variability of that parameter in the region. Vulnerability has been divided into five categories. In the end a weight has been assigned to each category map using AHP method and finally all six category maps have been overlaid and a unique drought vulnerability map has been developed. In the following sections, each parameter has been described in details.

2.1.1 Precipitation: One of the most important parameters in assessing drought vulnerability in a region is precipitation. Therefore, knowing its variability is vital in developing vulnerability maps. Average annual rainfall for East Azarbaijan is about $24 \mathrm{~cm} /$ year. There is a variation in the amount of rainfall between different stations which is from $17.9 \mathrm{~cm} /$ year to $34.74 \mathrm{~cm} /$ year. Rainfall data is used from sixteen stations across the region in ten years (2001-2011). The MSL elevation of recording stations varies from $736 \mathrm{~m}$ to $1950 \mathrm{~m}$. By using isohyetal method, the rainfall in the whole region is calculated. In Table 2, the vulnerability of the region is classified into 5 categories based on precipitation variation.

\begin{tabular}{|c|c|}
\hline Precipitation range $(\mathrm{mm})$ & Vulnerability category \\
\hline $32.5-38$ & 0.2 \\
\hline $28-32.5$ & 0.4 \\
\hline $23.5-28$ & 0.6 \\
\hline $18.5-23.5$ & 0.8 \\
\hline $13.5-18.5$ & 1 \\
\hline
\end{tabular}

Table 2- Average precipitation vulnerability category 
2.1.2 Temperature: Temperature is another important factor in assessing vulnerability due to its direct impact on transpiration. Due to the high elevation of a region from sea level (considering the fact that the temperature drops $1^{\circ} \mathrm{C}$ with the 100 meters increase in altitude) and the mountainous topography, cool weather is expected in area. Average annual temperature for East Azarbaijan varies from $8^{\circ}$ to $16^{\circ} \mathrm{C}$. Higher temperature will cause more evapotranspiration and can make the region more vulnerable. For vulnerability classification, the average temperature for each station is calculated in duration of time series. In Table 3, the classification of vulnerability based on the temperature is given.

\begin{tabular}{|c|c|}
\hline Temperature range $\left({ }^{\circ} \mathrm{C}\right)$ & Vulnerability category \\
\hline$<9.5$ & 0.2 \\
\hline $9.5-11$ & 0.4 \\
\hline $11-12.5$ & 0.6 \\
\hline $12.5-14$ & 0.8 \\
\hline$>14$ & 1 \\
\hline
\end{tabular}

Table 3- Temperature vulnerability category

2.1.3 Solar Radiation: Solar radiation is another factor that is considered because of its importance in energy conservation field issues and it is considered as one of the factors in evaluating evapotranspiration. Due to low number of solar radiation sites and lack of accuracy in direct measurement of solar radiation with old tools in Iran, a number of empirical formulas and methods have been developed to estimate daily or monthly global radiation at different places in the world. The availability of meteorological parameters, which are used as the input of radiation models, is the key factor in choosing the proper radiation models at any location.

Many researches have been done in this field and some methods such as Angstrom (1924), Paltridge (1976), Sabbagh (1977) and Daneshyar (1978) have been proposed for evaluating solar radiation each of which has its own input parameters.

In this study Sabbagh method has been used due to adaptability and availability of data in Iran. This model which is described in below is applicable to dry arid and semi-arid regions such as Iran.

Sabbagh formula for evaluating solar radiation is:

$$
R_{\text {est }}=0.06407\left(\mathrm{~K}_{\mathrm{g}}\right) \exp \left[\mathrm{L}\left(\frac{\mathrm{n}}{12}-\frac{\mathrm{RH}^{0.333}}{100}-\frac{1}{T_{\max }}\right)\right]
$$

where $\quad R_{e s t}=$ total daily global radiation $\left(\mathrm{MJ} \cdot \mathrm{m}^{-2}\right.$.day $\left.{ }^{-1}\right)$ $\mathrm{n}=$ monthly average daily real sunshine duration (hr) $\mathrm{RH}=$ relative humidity $(\%)$

$\mathrm{T}_{\max }=$ monthly average of daily maximum air temperature $\left({ }^{\circ} \mathrm{C}\right)$

$\mathrm{K}_{\mathrm{g}}=$ the geographical factor $\left(\mathrm{g} \cdot \mathrm{cal} \cdot \mathrm{cm}^{-2} \cdot \mathrm{day}^{-1}\right)$

$\mathrm{Kg}$ of Sabbagh method is suggested by Reddy (1971):

$K_{\mathrm{g}}=100\left(\lambda N+\psi_{i, j} \cos \mathrm{L}\right)$

where $\quad L=$ latitude of the place in degrees

$\mathrm{N}=$ monthly average of daily maximum possible sunshine duration in hour

$\lambda=$ latitude factor

$\psi_{\mathrm{i}, \mathrm{j}}=$ seasonal factor $\lambda$ is estimated as:

$$
\lambda=\frac{0.2}{(1+0.1 \mathrm{~L})}
$$

$\psi_{\mathrm{i}, \mathrm{j}}$ is seasonal factor ( $\mathrm{i}=1,2,3$ for inland station, coastal stations and hilly stations respectively while $\mathrm{j}=1,2,3, \ldots, 12$ is the month index from January to December) delivered in Table A (in appendix).

Sabbagh equation input data is obtained from ten (10) stations around the region in ten (10) years. Solar radiation has a direct relationship with transpiration. Higher values will cause more transpiration and so it is considered as higher vulnerable. Thus, vulnerability is classified in 5 categories which are shown in Table 4.

\begin{tabular}{|c|c|}
\hline $\begin{array}{c}\text { Total daily global radiation } \\
\text { range (MJ.m-2.day-1) }\end{array}$ & $\begin{array}{c}\text { Vulnerability } \\
\text { category }\end{array}$ \\
\hline $1007-1043$ & 0.2 \\
\hline $1043-1079$ & 0.4 \\
\hline $1079-1114$ & 0.6 \\
\hline $1114-1150$ & 0.8 \\
\hline $1150-1185$ & 1 \\
\hline
\end{tabular}

Table 4- Solar Radiation Vulnerability Category

2.1.4 Slope: Slope maps represent topography of the region. Larger slope could produce larger amount of runoff, therefore, less ground water storage could be produced. As a result, in this study larger slope is considered to be more vulnerable. This may not always be the case but it is assumed here and as also indicated by Slejko (2010). Slope in the region varies from 0 to 90 degrees which represents a wide topography in the region.

For slope variation, vulnerability is classified into 5 categories which are shown in Table 5.

\begin{tabular}{|c|c|}
\hline Slope range (degree) & Vulnerability category \\
\hline $0-5$ & 0.2 \\
\hline $5-12$ & 0.4 \\
\hline $12-20$ & 0.6 \\
\hline $20-35$ & 0.8 \\
\hline $35-90$ & 1 \\
\hline
\end{tabular}

Table 5- Slope Vulnerability Category

2.1.5 Land Use: The way the lands are used in a region has a direct impact on water resources and as result it is considered in the drought vulnerability analysis. Land use could influence on water resources through changes in catchment yields, infiltration rates, dissolved organic carbon and nutrient transfers (Weatherhead and Howden, 2009). In this study water demand for each land use type has been assumed as a factor that directly influences drought vulnerability. For instance, salt lands have low water demand and as a result it is considered to have the lowest vulnerability to drought. On the other hand, irrigated areas have a large water demand which makes them the most vulnerable land use type when it comes to having water shortages. Different land uses types have been recognized in the study region which are wetland, forest, fishery poll, woodland, range, mountain range, garden, urban, salt lake, dry farming, irrigated area, salt lands and bare lands. They have been categorized into 5 groups which are showed in Table 6 . 


\begin{tabular}{|c|c|}
\hline Land Use & Vulnerability category \\
\hline $\begin{array}{c}\text { Salt lands, bare lands, } \\
\text { mountain range }\end{array}$ & 0.2 \\
\hline $\begin{array}{c}\text { Wetlands, dense forest, good } \\
\text { range }\end{array}$ & 0.4 \\
\hline $\begin{array}{c}\text { Urban, moderate range, } \\
\text { moderate forest, dry farming }\end{array}$ & 0.6 \\
\hline Low forest, poor range & 0.8 \\
\hline $\begin{array}{c}\text { Irrigated area, lake, garden, } \\
\text { fishery pool }\end{array}$ & 1 \\
\hline
\end{tabular}

Table 6- Land Use Vulnerability Category

2.1.6 Ground Water Level: Ground water is an important source of water supply in the region, particularly at the time of drought. Therefore, ground water level is also considered for developing vulnerability maps. It should be noted that water storage in the surface reservoirs is also important but it is not included because: 1) surface water storage have discrete values and interpolation between its scattered values is not representative for regional vulnerability studies as presented here; 2) It doesn't have distribution characteristics all over the region and cannot be mapped like the other parameters. Table 7 shows the 5 vulnerability categories for groundwater level variation.

\begin{tabular}{|c|c|}
\hline Ground water level range $(\mathrm{m})$ & Vulnerability category \\
\hline$<15$ & 0.2 \\
\hline $15-33$ & 0.4 \\
\hline $33-54$ & 0.6 \\
\hline $54-75$ & 0.8 \\
\hline$>75$ & 1 \\
\hline
\end{tabular}

Table 7- Ground Water Level Vulnerability Category

\section{CASE STUDY}

The case study is East Azarbaijan province (Figure 1) which contains watersheds such as Aharchay, Sufichay, Tajyar and Shahrchay. As it is displayed in Figure 1, this province consists of 19 counties with a total area of approximately $47,830 \mathrm{~km}^{2}$. The data from 16 hydrological stations including rain gauge stations and groundwater level monitoring stations are used for evaluation of vulnerability.

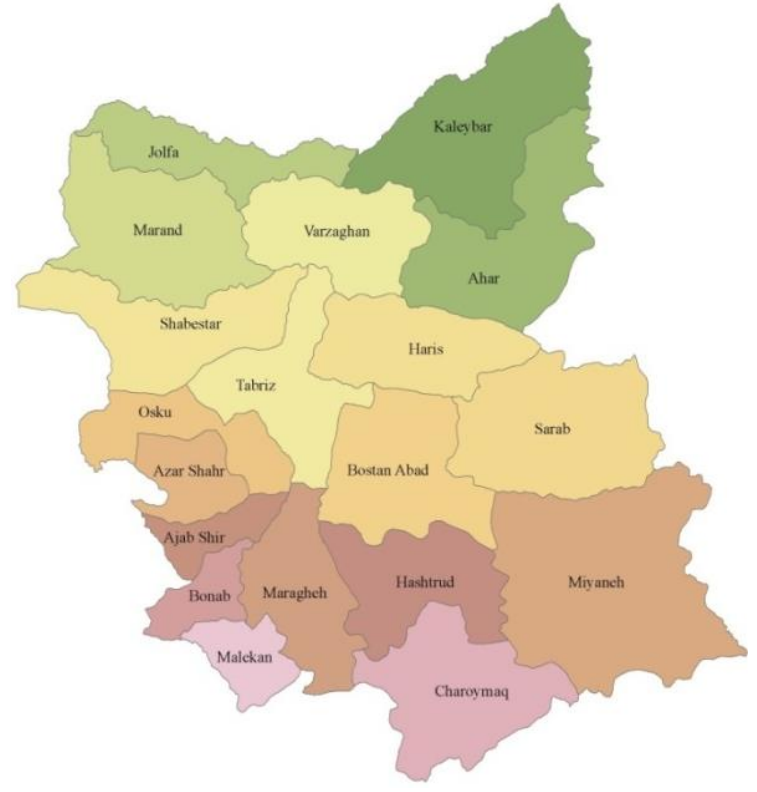

Figure 1- East Azarbaijan Province

\section{RESULTS}

In Figure A (in Appendix), the variation of each parameter (precipitation, temperature, solar radiation, slope, land use and groundwater) in vulnerability assessment is shown. These maps were obtained using ArcGIS software. For each map the variation is classified in five groups as it was mentioned in Table 2 to Table 7.

Finally, all 6 category maps were overlaid to produce total vulnerability map for the region. For overlaying, weights are assigned for the map of each parameter based on their importance and influence on drought vulnerability. AHP method has been used for this task which uses experts' opinions. Table 8 shows each category map weights.

\begin{tabular}{|c|c|}
\hline Parameter & Weight \\
\hline Precipitation & 0.25 \\
\hline Temperature & 0.15 \\
\hline Land use & 0.2 \\
\hline Ground water level & 0.2 \\
\hline Solar radiation & 0.15 \\
\hline Slope angle & 0.05 \\
\hline
\end{tabular}

Table 8- Category Maps Weights 


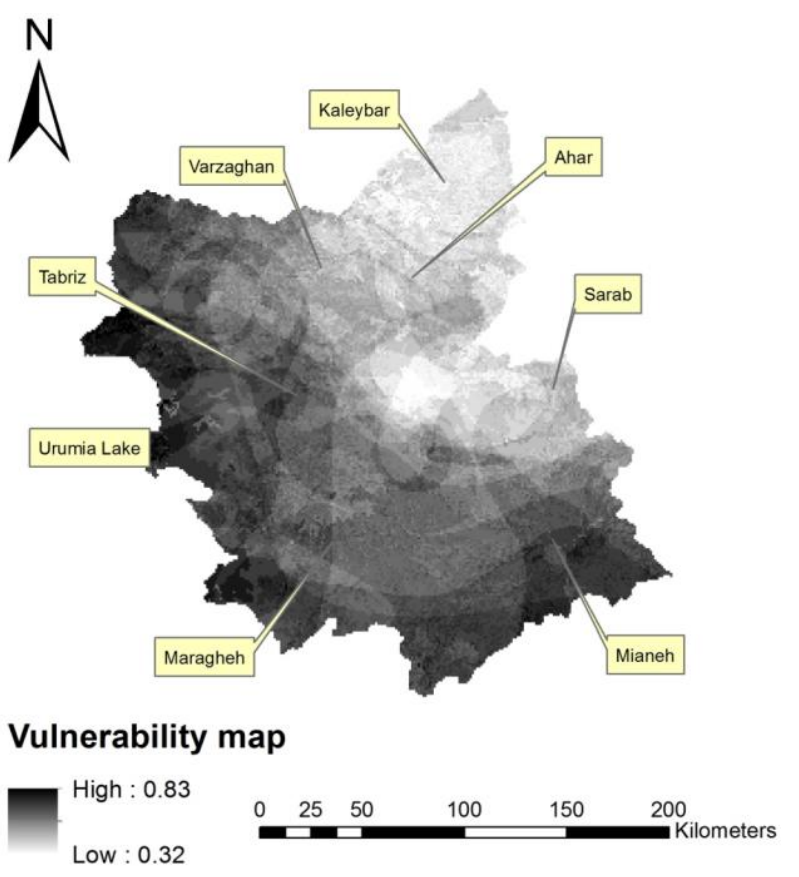

Figure 2- Final vulnerability map including some strategic locations

Figure 2 shows the final vulnerability variation of the region. As it can be seen the vulnerability almost increases gradually from east to west. The western part has the highest vulnerability value (nearly 0.83 ). This part is next to Urumia Lake. This lake has lost most of its resources during the last decades due to the over utilization of its resources causing excessive depletion in this lake. Table 9 shows vulnerability value of some important locations shown in Figure 2.

\begin{tabular}{|c|c|}
\hline Location & Vulnerability value \\
\hline Tabriz & 0.53 \\
\hline Varzaghan & 0.41 \\
\hline Kalrybar & 0.35 \\
\hline Sarab & 0.38 \\
\hline Mianeh & 0.68 \\
\hline Maragheh & 0.62 \\
\hline
\end{tabular}

Table 9- Vulnerability values for selected regions

On the other hand, the eastern part of Figure 2, particularly northeast part, has the lowest vulnerability value $(0.32)$. Considering the fact that this region is near Caspian sea with high amount of precipitation, the result seems reasonable.

It should be noted that most of the factors that were considered in vulnerability evaluation are greatly related to the intrinsic nature of the region. This means that these features cannot be changed easily. Therefore, drought occurrence is to some extend inevitable. In other word, preventing drought might not be achievable. A good idea in management of this hazard is focusing on resiliency of the region which shows how region is capable of facing this hazard in a timely manner. Resilient region has the ability to cope with drought and become more sustainable.

\section{SUMMARY AND CONCLUSION}

In this study, a drought vulnerability map has been created for East Azarbaijan based on 6 parameters of precipitation, temperature, solar radiation, slope, land use and ground water level. For this purpose each parameter is classified into 5 groups and their spatial distribution were mapped in GIS to show variability of that parameter. Maps have been weighted and then overlaid to provide drought vulnerability map. The results show that western and southern parts of the region are more vulnerable to drought and therefore more resources and strategies should be implemented in those parts of for drought preparedness planning the methodology of this study could be utilized in other arid and semiarid regions.

\section{REFERENCES}

Anderson, M. B. (1995). Vulnerability to disaster and sustainable development: A general framework for assessing vulnerability. Disaster Prevention for Sustainable Development: Economic and Policy Issues. Washington, DC: World Bank, 4159.

Angstrom, A. (1924). Solar and terrestrial radiation. Report to the international commission for solar research on actinometric investigations of solar and atmospheric radiation. Quarterly Journal of the Royal Meteorological Society,50(210), 121-126.

Bohle, H. G., Downing, T. E., \& Watts, M. J. (1994). Climate change and social vulnerability: toward a sociology and geography of food insecurity. Global Environmental Change, 4(1), 37-48.

Chang, T., (1990). Effects of Drought on Streamflow Characteristics. J. Irrig. Drain Eng., 116(3), 332-341.

Chang, T. J., Germain, R., \& Bartrand, T. A. (1997). Development of a GIS procedure for the study of evaporation and infiltration in case of drought. In Computing in Civil Engineering (pp. 606-614).ASCE.

Cutter, S. L., Boruff, B. J., \& Shirley, W. L. (2003). Social vulnerability to environmental hazards. Social science quarterly, 84(2), 242-261.

Daneshyar, M. (1978). Solar radiation statistics for Iran. Solar Energy, 21(4), 345-349.

Dziegielewski, B., Mee, W. R., Larson, K. R., (1992). Developing a long-term drought plan for Phoenix, JournalAmerican Water Works Association, Vol. 84, No. 10, pp. 46-51

Etkin D, Haque E, Bellisario L, Burton I (2004). An assessment of natural hazards and disasters in Canada.The Canadian natural hazards assessment project. Public safety and emergency preparedness Canada and environment Canada, Ottawa

Gallopín, G. C. (2006). Linkages between vulnerability, resilience, and adaptive capacity. Global environmental change, 16(3), 293-303.

Garen, D. C., (1993). Revised surface-water supply index for western United States, Journal of Water Resources Planning and Management, Vol. 119, No. 4, pp. 437-454

Iran Forests, Range, Watershed Management Organization, website:http://frw.org.ir/

Islamic Republic of Iran Meteorological Organization (IRIMO), website: http://www.irimo.ir/far/ 
Iran Water Resources Management Company, website: http://www.wrm.ir/

Jackson, Ivor, (2001). Drought Hazard Assessment and Mapping for Antigua and Barbuda: Post- Georges Disaster Mitigation Project in Antigua and Barbuda and St. Kitts and Nevis. A report prepared for the Organization of American States.

Karamouz , M., Torabi, S., Araghinejad, S., (2004). Analysis of Hydrologic and Agricultural Droughts in CentralPart of Iran, Journal of Hydrologic Engineering, 9(5), pp. 402-414.

Karamouz, M., (2008). Updating Water Resources and Consumption and Drought Management in Aharchay Watershed. Vol: 1 and 2, Tehran University press.

Karamouz, M., Rasuli, K., Nazif, S., (2009). Development of a Hybrid Index for Drought Prediction, Journal of Hydrologic Engineering, 14(6), pp. 617-627.

Karamouz, M., Nazif, S., Ahmadi, A., (2013). Development of Integrated Drought Evaluation and Monitoring System : Case Study of Aharchay River Basin , Journal of Hydrologic Engineering, 18(7), pp. 897-910.

Keenan, S. P., \& Krannich, R. S. (1997). The Social Context of Perceived Drought Vulnerability1. Rural sociology, 62(1), 6988 .

Klein, R. J., Nicholls, R. J., \& Thomalla, F. (2003). Resilience to natural hazards: How useful is this concept? Global Environmental Change Part B: Environmental Hazards, 5(1), $35-45$.

Keyantash, J., \& Dracup, J. A. (2002). The quantification of drought: an evaluation of drought indices. Bulletin of the American Meteorological Society, 83(8), 1167-1180.

Liu, W. T., \& Kogan, F. N. (1996). Monitoring regional drought using the vegetation condition index. International Journal of Remote Sensing, 17(14), 2761-2782.

Lourens, U. W. (1995). A System for Drought Monitoring and Severity Assessment, Ph.D. dissertation. Faculty of Agriculture, Department of Agrometeorology, University of the Orange Free State.

Moring, A., Nemeth, A, Bihari, Z, (2012). Estimation and mapping of drought vulnerability on the basis of climate, land use and soil parameters using GIS technique, Final conference of DMCSEE project, Ljubljana

Neema, Li, Diana, Helena, Walid, (2010). UNU-EHS Block Course From Vulnerability in Resilience in Disaster Risk Management, United Nation University.

Palmer, W. C., Fieldhouse, D. J., (1965). The Climate of the Northeast: Meteorological and agricultural drought. Agricultural Experiment Station [Newark, Delaware] Bulletin 353. Newark, Delaware: University of Delaware, Agricultural Experiment Station.

Paltridge, G. W., \& Proctor, D. (1976). Monthly mean solar radiation statistics for Australia. Solar Energy, 18(3), 235-243.

Rasmussen, E.U., Dickinson, R.E., Kutzbach, J.E., and Cleaveland, M.K. (1993). 'Climatology.'Chapter 2. In:
D.R.Maidment (ed.) Handbook of Hydrology. McGraw-Hill Inc, New York, pp 2.1-2.44.

Reddy, S. J. (1971). An empirical method for the estimation of total solar radiation, Solar Energy, vol. 13, no. 2, pp. 289-290, 1971.

Rossi, G., Benedini, M., Tsakiris, G., \& Giakoumakis, S. (1992). On regional drought estimation and analysis. Water Resources Management, 6(4), 249-277.

Rossi, G. (2000). Drought mitigation measures: a comprehensive framework in drought and drought mitigation in Europe (pp. 233-246). Springer Netherlands.

Sabbagh, J. A., Sayigh, A. A. M., \& El-Salam, E. M. A. (1977). Estimation of the total solar radiation from meteorological data. Solar Energy, 19(3), 307-311.

Shafer, B. A., and Dezman, L. E., (1982). Development of a surface water supply index (SWSI) to assess the severity of drought conditions in snow pack runoff area. Proc., Western Snow Conf., Colorado, State University, Fort Collins, Colo., pp. 164-175.

Shin, H. S., Salas, J. D., (2000). Regional Drought Analysis Based on Neutral Networks, Journal of Hydraulic Engineering, Vol. 5, No. 2, pp. 145-155.

Slejko, M., Gregoric, G., Bergant, K., \& Stanic, S. (2010). Assessing and Mapping Drought Vulnerability in Agricultural Systems-A case Study for Slovenia. In 10th EMS Annual Meeting, 10th European Conference on Applications of Meteorology (ECAM) Abstracts, held Sept. 13-17, 2010 in Zürich, Switzerland. http://meetings. copernicus. org/ems2010/, id. EMS2010-586 (Vol. 1, p. 586).

Statistical Center of Iran, website:http://www.amar.org.ir/

Turner, B. L., Kasperson, R. E., Matson, P. A., McCarthy, J. J., Corell, R. W., Christensen, L., ... \& Schiller, A. (2003). A framework for vulnerability analysis in sustainability science. Proceedings of the national academy of sciences, 100(14), 8074-8079.

Weatherhead, E. K., \& Howden, N. J. K. (2009). The relationship between land use and surface water resources in the UK, Land Use Policy, 26, S243-S250.

Wilhite, D. A., \& Glantz, M. H. (1985). Understanding: the drought phenomenon: the role of definitions. Water international, 10(3), 111-120.

Wilhelmi, O. V. (1999). Methodology for assessing vulnerability to agricultural drought: A Nebraska case study (Doctoral dissertation, University of Nebraska, Lincoln).

Zhou, H., Wan, J., \& Jia, H. (2010). Resilience to natural hazards: a geographic perspective, Natural Hazards, 53(1), 2141.

Smith, J., 1987a. Close range photogrammetry for analyzing distressed trees. Photogrammetria, 42(1), pp. 47-56.

Smith, J., 1987b. Economic printing of color orthophotos. Report KRL-01234, Kennedy Research Laboratories, Arlington, VA, USA. 
The International Archives of the Photogrammetry, Remote Sensing and Spatial Information Sciences, Volume XL-1/W5, 2015 International Conference on Sensors \& Models in Remote Sensing \& Photogrammetry, 23-25 Nov 2015, Kish Island, Iran

Smith, J., 1989. Space Data from Earth Sciences. Elsevier, Amsterdam, pp. 321-332.

Smith, J., 2000. Remote sensing to predict volcano outbursts. In: The International Archives of the Photogrammetry, Remote Sensing and Spatial Information Sciences, Kyoto, Japan, Vol. XXVII, Part B1, pp. 456-469. 
The International Archives of the Photogrammetry, Remote Sensing and Spatial Information Sciences, Volume XL-1/W5, 2015 International Conference on Sensors \& Models in Remote Sensing \& Photogrammetry, 23-25 Nov 2015, Kish Island, Iran

APPENDIX

\begin{tabular}{|c|c|c|c|c|c|c|c|c|c|c|c|c|}
\hline & 1 & 2 & 3 & 4 & 5 & 6 & 7 & 8 & 9 & 10 & 11 & 12 \\
\hline$\psi_{1}$ & 1.28 & 1.38 & 1.54 & 1.77 & 2.05 & 2.30 & 2.48 & 2.41 & 2.36 & 1.73 & 1.38 & 1.17 \\
\hline$\psi_{2}$ & 1.46 & 1.77 & 2.05 & 2.15 & 2.05 & 2.05 & 2.10 & 2.17 & 2.14 & 1.96 & 1.60 & 1.43 \\
\hline$\psi_{3}$ & 1.60 & 1.81 & 2 & 2.17 & 2.25 & 2.26 & 2.24 & 2.20 & 2.10 & 1.92 & 1.74 & 1.60 \\
\hline
\end{tabular}

Table A- Seasonal factor by Reddy (1971)

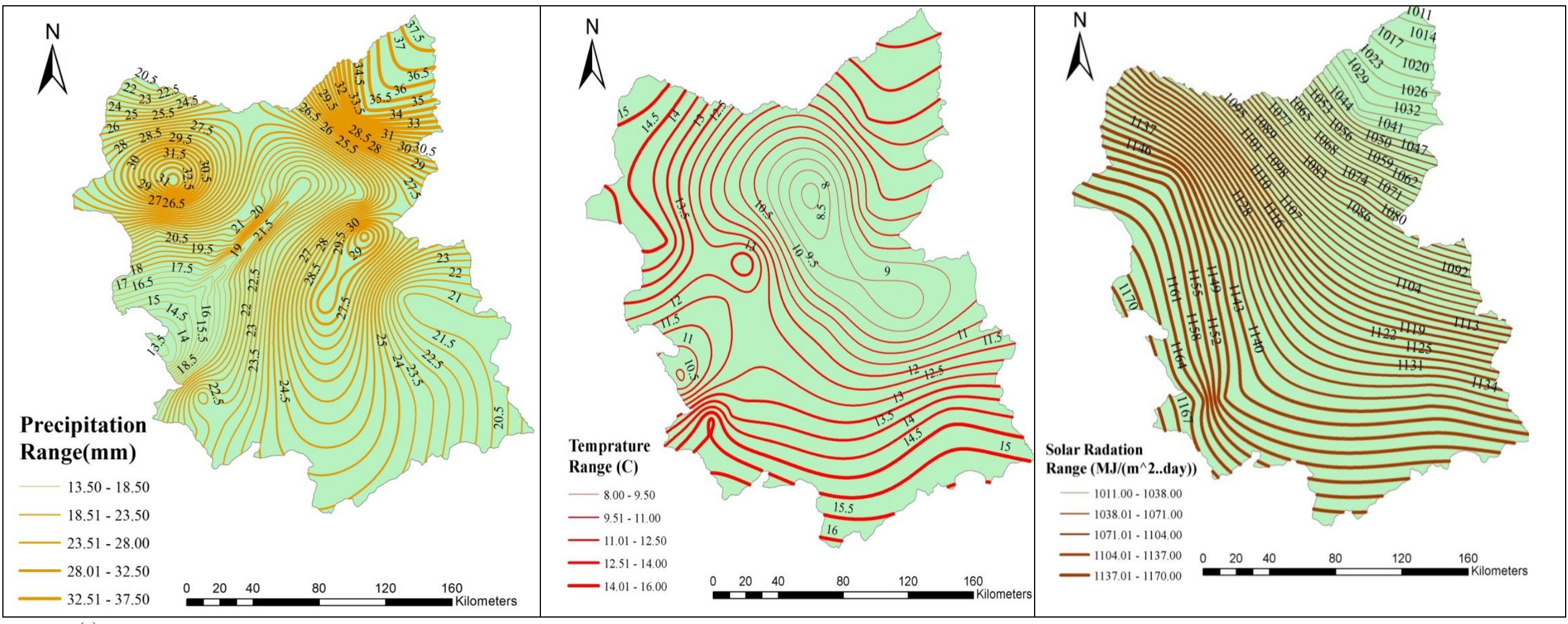

(a) 


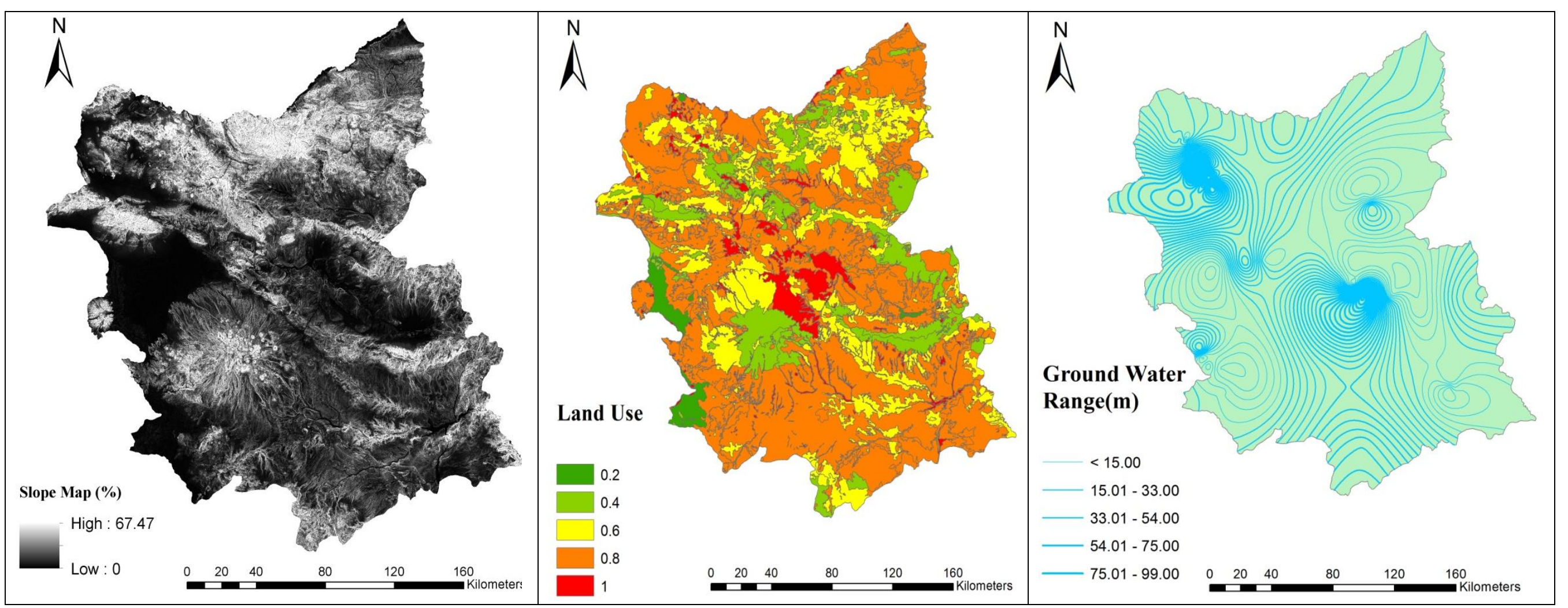

(b)

Figure A- Variation map of the effective parameters in drought vulnerability assessment, (a): Precipitation, Temperature and solar radiation range map, (b): Solar map, Land use and Ground water level map 